\title{
INVESTIGATING PERCEPTIONS OF PATIENTS ON HEALTHCARE PRICING WITHIN THE PRIVATE HEALTHCARE SECTOR IN SRI LANKA
}

\author{
Kanchana Sajeeva Narangoda, Estie Kruger, Marc Tennant
}

School of Human Sciences, University of Western Australia, Perth, Australia

Correspondence: sajeevaksn@gmail.com

\begin{abstract}
Demand for private sector healthcare services in Sri Lanka is on the rise. This is very evident from the increase in the number of registered private healthcare institutions from 1990 to 2017. [1,2]

With the increasing utilization of private sector healthcare services, various qualitative factors, and service-related issues associated with the healthcare delivery system have become common debates. A major concern, patients have expressed, is about the fees charged by doctors and hospitals.
\end{abstract}

Principle aim of this study was to investigate the perceptions of patients on healthcare pricing within the private healthcare sector in Sri Lanka.

The target population of the study was defined as Sri Lankans who have been inpatients in private hospitals within the past year. The focus districts were Colombo, Kandy, and Galle. These 3 districts represented nearly $60 \%$ of the total private sector bed capacity.

From each district, three main private hospitals were selected. Over 700 patients were invited to participate, 246 surveys were completed, and 215 were retained as 31 had excessive missing and/or unclear data.

In all 3 districts the majority of patients were either dissatisfied with or remained neutral (69\%) on the hospital fees, (66\%) on doctor's fees, $(74 \%)$ on the overall price they ended up paying, $(76 \%)$ on whether they think the healthcare services they received are value for money.

This study did not investigate the reasons or the factors that may affect the satisfaction or dissatisfaction of patients towards the fees they paid.

Multiple factors can affect patient's perception on the fees they paid. With negative perception on the above it can be concluded that there is sufficient evidence to challenge private sector healthcare satisfaction level vs price/fees equilibrium in Sri Lanka.

\section{KEYWORDS}

Patient perception, value, pricing, private healthcare, fees 
The total number of private hospital beds in Sri Lanka has increased from an estimated 2000 in 1990 to 4200 in 2011 . [1] In 2017 it stands at 4686. [2] The registered number of private healthcare institutions had gone up from 656 in 2013 to 1103 in 2017. [2] These figures provide ample evidence that demand for private sector healthcare services in Sri Lanka are on the rise.

The public sector in Sri Lanka carries the bulk of the burden on delivering healthcare services to a population of nearly 22 million people. A total of 628 public sector hospitals facilitated almost 7 million $(6,910,249)$ inpatient admissions in 2017, whereas 141 private hospitals accounted for 135,000 inpatient admissions during the same year [2] . However, studies done in 2011 state 266,000 inpatient admissions in the private sector. [1]

Bed capacity in public hospitals stands at 83,275 , and 4686 in the 141 private hospitals, which is $5.62 \%$ of the total government bed capacity. [2]

With the increasing utilization of private sector healthcare services, various qualitative factors, as well as servicerelated issues associated with the healthcare delivery system within the private sector have become common debates among the general public. One of the concerns patients have expressed, is about the fees charged by doctors and hospitals.

Several studies have been conducted in Sri Lanka to ascertain the quality of inpatient and outpatient care in private and public sectors. [3,4] However little information exist on understanding the perceptions of patients on the fees they pay on obtaining private sector healthcare services.

While the plethora of approaches to studying patient satisfaction represents intense interest in giving voice to the patients in the developed world, in developing countries, patients face limited interest. Few studies have sought patient views and there is little effort to involve them in measuring satisfaction or defining health service standards. $[5,6,7,8]$

It is the belief of many researchers that a patient who endures the physical, psychological, social and economic experience during the overall health service delivery

process would be able to make an appropriate evaluative judgment of how they were treated, as reflected in their overall satisfaction or dissatisfaction measures. [5]

It has long been regarded that as part of assessing the quality of healthcare services, the process, structure, and outcome all play vital roles. Patient perceptions, satisfaction and acceptability of the healthcare process have become an important part of the assessment process. [9]

In Sri Lanka more can be done to understand patients perceptions on health care pricing and the association between price paid by the patients and the perceived quality of the services received. There is room to challenge the price-quality connection as both health care prices and health care quality can be difficult to interpret [10]. The fact that there is a debate among consumers on healthcare pricing in Sri Lanka indicate that patient perceptions on healthcare pricing and the perceived opinions on quality of care received should be scientifically investigated. It can also be argued that any negativity on the overall healthcare experience can adversely affect patient perceptions on the price paid on obtaining the healthcare service.

Studies done by [10] suggest that consumers of healthcare services, at all levels, have justification in challenging the pricing of healthcare services considering the quality scores available in the public domain.

Against this background the aim of this study was to investigate the perceptions of patients on healthcare pricing within the private healthcare sector in Sri Lanka.

\section{METHODS}

\section{ETHICS:}

A permission letter was obtained from the Ministry of Health and Indigenous Medical services, Sri Lanka to approach private hospitals (AD19/02/42). In Sri Lanka, all private hospitals come under the direct purview of the private sector health regulatory council operating under the Ministry of Health. Ethical approval to conduct the study was also obtained from the Ethics Committee of the University of Western Australia (RA/4/20/5489), and local ethical clearance was obtained from the International Institute of Health Sciences, Sri Lanka (BI/ERC/265). 


\section{PARTICIPANTS AND PATIENT CONSENT:}

The target population of the study was defined as Sri Lankans who have been inpatients in private hospitals in Sri Lanka within the past year. The focus districts were Colombo, Kandy, and Galle. These 3 districts represented nearly $60 \%$ of the total private sector bed capacity. [2]

Stratified sampling was carried out, to randomly select 15 patients ( 5 from each district) who had undergone private sector health care treatment within a period of one year. Interviews were conducted with these patients with the primary objective of planning the questionnaire.

Secondly, a preliminary questionnaire was first developed in English and then translated into Singhalese and Tamil, the mother tongues of Sri Lankans. The questionnaire was pretested several times to arrive at proper wording, presentation, format, length and the order of questions. Initial feedback received from participants in a small pilot survey were used to improve the questionnaire.

From each district three main private hospitals were selected, and the letter of permission obtained from the Ministry of Health was forwarded to obtain the support and cooperation of each hospital in conducting the survey. These hospitals informed their in-house patients who were either discharged, or about to be discharged within a period of 2 months and provided them with information about this survey and invited them to take part. The patients who gave their consent was contacted and interviewed for the purpose of the research. While the interview was conducted predominately by telephone, patients who indicated that they preferred a home visit was visited at home and the survey was conducted accordingly. Social media (Facebook, and WhatsApp) were also used to invite recently discharged patients to complete questionnaires via Survey monkey. Respond rates through these channels were very low, however. Overall, across the three districts over 700 patients were invited to participate, 246 surveys were completed (35\%), and 215 were retained as 31 had excessive missing data and/or unclear data. Response rates were Colombo $36 \%$, Galle $33 \%$ and Kandy $36 \%$

\section{QUESTIONNAIRE:}

The following four questions were asked:

1. In my opinion, the hospital fee was reasonable.

2. In my opinion, the doctor's fee was reasonable.

3. Overall, I was satisfied with the price I paid.

4. I think the amount I paid for the services I received was value for money.

Responses were provided on a Likert scale, and for each statement options were Strongly Disagree (SD), Disagree (D), Neutral (N), Agree (A), and Strongly Agree (SA). Categories of $S D$ and $D$, and $A$ and $S A$ were combined, in order to determine significant differences between districts in terms of responses.

\section{STATISTICAL ANALYSIS:}

Data were collected using Excel 2019, for descriptive analysis determining means and standard deviations, SPSS version 27 were used. Chi-square tests were used to compare categorical data between hospitals. Statistical significance was set at $95 \%$, with $\mathrm{p}$-values $<0.05$ considered statistically significant.

TABLE 1: DIFFERENCES IN RESPONSES BY DISTRICTS IN RELATION TO EACH QUESTION.

\begin{tabular}{llllllll}
\hline VARIABLES & DISTRICT & N & MEAN (SD) & SA+A(\%) & N(\%) & D+SD(\%) & $\begin{array}{l}\text { P* } \\
\text { (VARIABLE } \\
\text { VS } \\
\text { Hospital fee }\end{array}$ \\
& & & & & & & \\
& Colombo & 80 & $3.14(1.06)$ & $20(25)$ & $25(31)$ & $35(44)$ & 0.040 \\
& Kandy & 70 & $3.14(1.04)$ & $24(34)$ & $18(26)$ & $28(40)$ & \\
& Galle & 65 & $3.15(1.09)$ & $22(34)$ & $17(26)$ & $26(40)$ & \\
& All & 215 & $3.14(1.06)$ & $66(31)$ & $60(28)$ & $89(41)$ & \\
& & & & & & & \\
\hline Doctor's fee & Colombo & 80 & $3.19(1.10)$ & $26(33)$ & $20(25)$ & $34(43)$ & 0.628 \\
& Kandy & 70 & $3.10(1.08)$ & $27(39)$ & $16(23)$ & $27(39)$ & \\
& Galle & 65 & $3.02(1.01)$ & $22(34)$ & $24(37)$ & $19(29)$ & \\
& All & 215 & $3.11(1.07)$ & $75(35)$ & $60(28)$ & $80(37)$ & \\
& & & & & & \\
\hline
\end{tabular}




\begin{tabular}{llllllll}
\hline $\begin{array}{l}\text { Overall } \\
\text { satisfaction } \\
\text { of fees paid }\end{array}$ & Colombo & 80 & $3.40(1.17)$ & $19(24)$ & $26(33)$ & $35(44)$ & 0.073 \\
& Kandy & 70 & $3.23(0.98)$ & $18(26)$ & $24(34)$ & $28(40)$ & \\
& Galle & 65 & $3.19(1.03)$ & $20(31)$ & $16(25)$ & $29(45)$ & \\
& All & 215 & $3.28(1.07)$ & $57(27)$ & $66(31)$ & $92(43)$ & \\
\hline Value for money & Colombo & 80 & $3.49(0.97)$ & $11(14)$ & $32(40)$ & $37(46)$ & 0.183 \\
& Kandy & 70 & $3.21(1.08)$ & $22(31)$ & $20(29)$ & $28(40)$ & \\
& Galle & 65 & $3.14(1.04)$ & $21(32)$ & $18(28)$ & $26(40)$ & \\
& All & 215 & $3.29(1.03)$ & $54(25)$ & $70(33)$ & $91(42)$ & \\
& & & & & & & \\
\hline
\end{tabular}

*Chi-square, $\mathrm{p}<0.05$ deemed significant

TABLE 2: FREQUENCIES OF RESPONSES TO INDIVIDUAL QUESTIONS ACROSS ALL DISTRICTS.

\begin{tabular}{|c|c|c|c|c|c|c|c|}
\hline & & SA & $\mathbf{A}$ & $\mathbf{N}$ & D & SD & TOTAL (\%) \\
\hline \multirow{4}{*}{ Hospital fee } & Colombo & $8(10 \%)$ & $12(15 \%)$ & 25 (31\%) & $31(39 \%)$ & $4(5 \%)$ & 80 (100\%) \\
\hline & Kandy & $1(1 \%)$ & 23 (33\%) & $18(26 \%)$ & $21(30 \%)$ & $7(10 \%)$ & 70 (100\%) \\
\hline & Galle & 2 (3\%) & 20 (31\%) & 17 (26\%) & $18(28 \%)$ & 8 (12\%) & 65 (100\%) \\
\hline & All & $11(5 \%)$ & $55(26 \%)$ & $60(28 \%)$ & $70(32 \%)$ & $19(9 \%)$ & 215 (100\%) \\
\hline \multirow{4}{*}{ Doctor's fee } & Colombo & $3(4 \%)$ & $23(29 \%)$ & $20(25 \%)$ & $24(30 \%)$ & $10(12 \%)$ & 80 (100\%) \\
\hline & Kandy & $1(1 \%)$ & $26(37 \%)$ & $16(23 \%)$ & $19(27 \%)$ & $8(12 \%)$ & 70 (100\%) \\
\hline & Galle & $2(3 \%)$ & 20 (31\%) & $24(37 \%)$ & $13(20 \%)$ & $6(9 \%)$ & 65 (100\%) \\
\hline & All & $6(3 \%)$ & 69 (32\%) & $60(28 \%)$ & $56(26 \%)$ & 24 (11\%) & 215 (100\%) \\
\hline \multirow{4}{*}{$\begin{array}{l}\text { Overall } \\
\text { satisfaction } \\
\text { on fees paid }\end{array}$} & Colombo & $3(4 \%)$ & $16(20 \%)$ & $26(32 \%)$ & $16(20 \%)$ & 19 (24\%) & 80 (100\%) \\
\hline & Kandy & $1(1 \%)$ & 17 (24\%) & $24(34 \%)$ & $21(30 \%)$ & 7 (10\%) & 70 (100\%) \\
\hline & Galle & $2(3 \%)$ & $18(28 \%)$ & $16(25 \%)$ & $24(37 \%)$ & $5(7 \%)$ & 65 (100\%) \\
\hline & All & $6(3 \%)$ & $51(24 \%)$ & $66(31 \%)$ & $61(28 \%)$ & 31 (14\%) & 215 (100\%) \\
\hline \multirow{4}{*}{ Value for money } & Colombo & $1(1 \%)$ & 10 (13\%) & $32(40 \%)$ & $23(29 \%)$ & $14(17 \%)$ & 80 (100\%) \\
\hline & Kandy & $1(1 \%)$ & $21(30 \%)$ & $20(29 \%)$ & $18(26 \%)$ & $10(14 \%)$ & 70 (100\%) \\
\hline & Galle & $2(3 \%)$ & 19 (29\%) & $18(28 \%)$ & $20(32 \%)$ & $6(9 \%)$ & 65 (100\%) \\
\hline & All & $4(2 \%)$ & 50 (23\%) & 70 (33\%) & $61(28 \%)$ & 30 (14\%) & 215 (100\%) \\
\hline
\end{tabular}

\section{RESULTS}

In all 3 districts the majority of patients were either FIGURE 1: RESPONSES OBTAINED FOR SATISFACTION ON HOSPITAL FEE

dissatisfied with or remained neutral $(69.3 \%)$ on the hospital fees they have paid. In Colombo $75 \%$ of the patients were either dissatisfied or remained neutral, whereas the corresponding figures were $66 . \%$ and $66 \%$ in Galle and Kandy. (Figure 1, Tables 1 and 2)

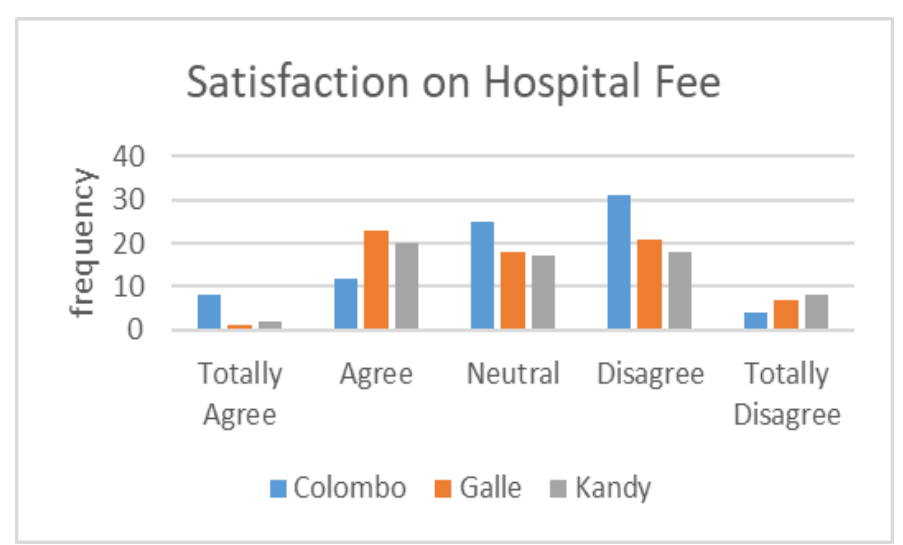


There was a significant difference on patient satisfaction ( $p$ = 0.016) between Colombo and Kandy, and between Colombo and Galle ( $p=0.033$ ) on hospital fees. Galle and Kandy patients were comparatively more satisfied than Colombo district patients on the price they paid as hospital fees. This finding does not eradicate the notion of overall dissatisfaction or remaining neutral on hospital fees across these three districts.

In all 3 districts a majority of patients were either dissatisfied or remained neutral (66\%) on doctor's fees. In Colombo district $(68 \%)$ of the patients were either dissatisfied or remained neutral on doctor's fees, whereas in Galle (69\%) and in Kandy (61\%) were the corresponding figures. There were no significant differences between the districts on doctor's fees. Thus, clearly establishing the notion that the majority of patients were not satisfied on the price paid as doctors' fees across the 3 districts. (Figure 2, Tables 1 and 2)

\section{FIGURE 2: RESPONSES OBTAINED REGARDING SATISFACTION ON DOCTOR'S FEE}

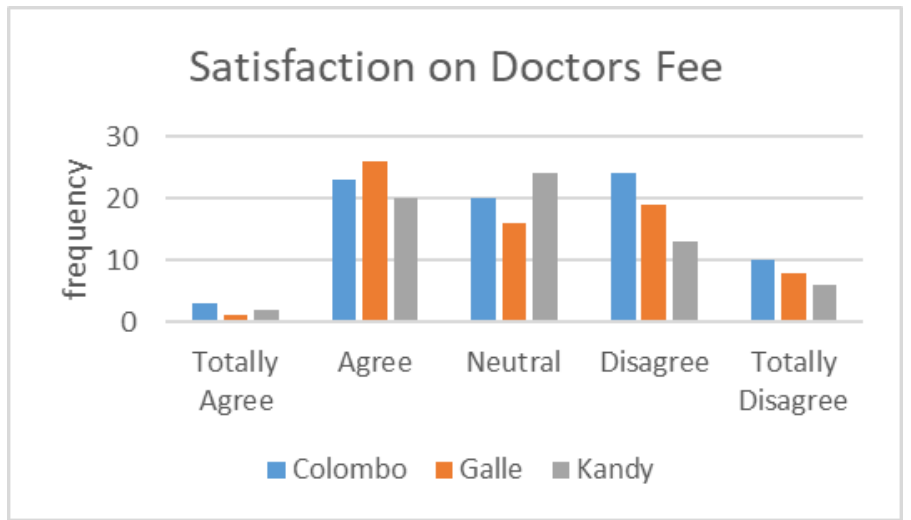

Almost three quarters (74\%) of patients across Colombo, Kandy and Galle districts either remained neutral or were dissatisfied with the overall price they ended up paying when they were hospitalized. In Colombo (76\%), Galle (71\%) and Kandy (74\%) most participants were clearly dissatisfied or remained neutral with the overall fees they have paid to obtain healthcare services. There were no significant differences between the districts on the opinion of patients on the overall fees they paid to obtain healthcare services. (Figure 3, Tables 1 and 2)
FIGURE 3: RESPONSES OBTAINED ON OVERALL SATISFACTION ON PRICING

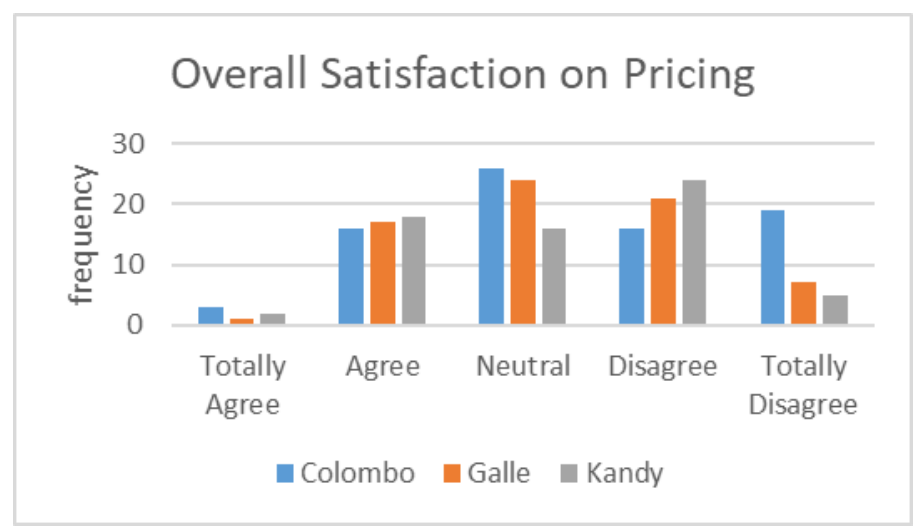

Three quarters (76\%) $(75.82 \%)$ of patients remained either neutral or dissatisfied when questioned whether they think the healthcare services they received are value for money. In Colombo district $86 \%$ of the patients were clearly dissatisfied or remained neutral whereas in Galle $71 \%$ and Kandy $69 \%$ were the corresponding figures. There were no significant differences between the districts on patient opinions on whether the healthcare services they received were value for money. (Figure 4, Tables 1 and 2)

\section{FIGURE 4: RESPONSES OBTAINED ON VALUE FOR MONEY}

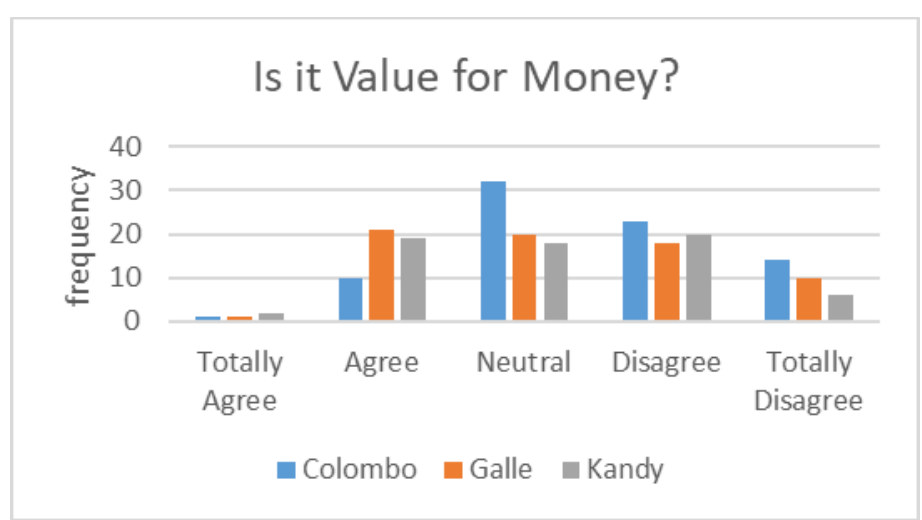

The mean values across all four variables (Hospital Fee, Doctor Fee, Satisfaction on overall fees paid by patients and Value for money), for all three districts were between 3 and 4 (between neutral and disagree) which indicates average respondents' opinion are between neutral and disagree. (Table 1) 
In this study patient perceptions on doctors' fees, hospital fees, overall fees paid and whether fees paid were value for money in comparison to the health outcome, were investigated. The majority of patients were either dissatisfied or remained neutral on all the above elements. Many studies have been conducted internationally to understand patient perceptions on healthcare quality, patient satisfaction with health services, how healthcare quality can be assessed and the choice factors of healthcare services. $[5,11,12,13]$

Research identified many factors that can affect patient satisfaction: reliability, responsiveness, assurance, tangible factors such as physical infrastructure, communication, empathy, orderly management of healthcare services, cost and availability/access are some of the main facets. [5]

The principal focus of this study was to establish patient perceptions towards healthcare pricing/fees across three main districts (Colombo, Kandy and Galle), which represents nearly $60 \%$ of the private sector bed capacity in Sri Lanka. It can be argued that perceived satisfaction with quality of healthcare can influence patient perception on the fees they paid. This research revealed that the patients' perceptions on fees paid by them to obtain the healthcare services were predominantly neutral or dissatisfied.

This study did not investigate the reasons or the factors behind the satisfaction or dissatisfaction of patients towards the fees they paid, the principal aim was to establish the perceptions among patients towards healthcare pricing/fees. However, the reasons behind why patients are remaining neutral or dissatisfied towards pricing should be further investigated using a larger cohort of patients.

In Sri Lanka transparency of healthcare pricing or obtaining an estimated healthcare pricing before treatment in private sector is not very well established. To this extent developing a mechanism through the private sector healthcare regulator on measuring service quality and patient satisfaction would be the starting points towards establishing a better system on maintaining healthcare pricing transparency.

\section{DOCTOR'S FEE}

This study revealed patient perceptions on the doctor's fee was between neutral and dissatisfied. Even though this study or any other Sri Lankan study had not investigated the exact reasons for the dissatisfaction, some of the international studies have revealed the service orientation of doctors is a strong influencer in patient satisfaction. [5] In the Sri Lankan private sector most of the specialist doctors serve multiple hospitals, as a result there may be a chance of doctors' service orientation towards patients getting affected due to high workload. Studies done by [11] and [14] also identified long waiting times and insufficient consultation time as factors contributing to patient dissatisfaction towards doctors. Even though not investigated directly in this study the above factors may hold true in Sri Lanka as well.

International studies reveal when patients decide to obtain private healthcare services, price is not a primary concern, [13] but patients do expect a higher level of service from private sector healthcare, and this phenomenon may hold true in Sri Lanka as well. However, in the more affluent western world [15] and [16] suggest that healthcare consumers have become much more sensitive to costs, despite health insurance coverage.

Affordability among the patients who seek private sector healthcare is definitely higher than the patients who access free public sector healthcare in Sri Lanka. Regulators and policy makers must recognise the fact that patients who patronize private sector healthcare may expect a higher quality of service.

Studies reveal that there is room to challenge the price to quality connection, as both healthcare fees/prices and quality of care can be difficult to interpret. Healthcare costs, prices/fees and quality can often be difficult to isolate and measure [10] In Sri Lanka healthcare regulators should play an important role in investigating whether there are any instances of overpricing and establishing a better framework to address any complaints from patients who are dissatisfied with the fees they paid.

\section{HOSPITAL FEES}

This study revealed that the majority of patients, in all three districts, were either dissatisfied or remained neutral on hospital fees. Sri Lankan private sector hospital fees comprise of nursing care, facility utilization fee, medication fees and investigation fees. Nursing care remains a vital component among the above. International studies reveal 
nursing care plays a significant contribution towards patient satisfaction [5] Even though scientifically not proven in Sri Lanka, international studies reveal patients can become very dissatisfied with poor behavior and inefficiency of nurses. [11]

It is very important that the regulator establishes a proper framework to ascertain quality of care provided by the nursing staff within private sector healthcare in Sri Lanka. With less regulation for nursing care within private sector nursing, nurses training and further education opportunities can become compromised. This problem can become a major limitation factor to improve private sector healthcare in Sri Lanka to challenge international competition coming from neighboring countries to attract patients from Sri Lanka.

The mechanisms on which hospitals charge patients on facility utilization, differs from hospital to hospital. There is no evidence to suggest in the public domain that the exact costs incurred by hospitals are properly investigated by the healthcare regulator and more scientific research should be carried out to establish a proper pricing mechanism to guide hospital operators to arrive at pricing. Lack of transparency in this area leaves room for patients to become suspicious on the fees charged by the hospital authorities. There is a high likelihood that all the above factors contribute to the dissatisfaction on hospital fees by patients.

Laboratory investigations, other investigations and medication fees also contribute towards patient's dissatisfaction with hospital fees. Lack of transparency and patient's lack of understanding on scientific terms and limited efforts made by the hospital authorities to explain facts to the patients can contribute to dissatisfaction. Here again the role of the private sector healthcare regulator is vital to improve the transparency. However more scientific research is needed to identify exact areas of concerns among the patients.

Interestingly this study also reveals that Colombo district patients are comparatively more dissatisfied than Kandy and Galle district patients $(p<0.04)$ on hospital fees. This finding should be investigated further since hospital fees represents many facets such as nursing fees, medication and investigation fees and hospital facility utilization fees. Whether this difference is due to over pricing in Colombo or due to better service levels in Kandy and Galle should be further investigated. However, it's a common observation that Colombo attracts a larger patient's number than the two other districts and as a result the quality of care delivered from comparatively busy hospitals have the potential to vary.

\section{VALUE FOR MONEY AND PERCEPTION ON OVERALL FEES PAID ON OBTAINING HEALTHCARE SERVICES}

In all three districts $76 \%$ of patients believe that the healthcare services they received from private sector were not value for money in comparison to the health outcome. $86 \%$ of patients in Colombo district thought the same. In any industry, consumers tend to correlate the price with the quality of the product or the service they consume/receive. The common notion being higher the price better the quality, and this may hold true in healthcare as well

\section{LIMITATIONS OF THE STUDY}

This study did not investigate the reasons or the factors that may affect the satisfaction or dissatisfaction of patients towards the fees they paid, the principal aim was to establish the perceptions among patients towards healthcare pricing/fees. However, the reasons behind why patients are remaining neutral or dissatisfied towards pricing should be further investigated using a larger cohort of patients and questioning more deeply into the multiple areas of concern among patients on the quality of care they received and on the overall service orientation of healthcare workers.

Low response rates resulted in a smaller than anticipated sample size, and subsequent work to establish reasons for perceptions should include larger samples of patients.

The mechanisms on which hospitals charge patients on nursing fees, facility utilization, Laboratory investigations, other investigations and medication may differ from hospital to hospital. There is no evidence to suggest that the exact costs incurred by hospitals are properly investigated. More scientific research should be carried to identify exact areas of concerns among the patients on the above factors and to investigate the mechanisms or the pricing formulas used by hospital authorities on pricing.

\section{CONCLUSION}

This study found patient's perception was either dissatisfaction or remaining neutral, on doctors' fees, hospital fees, overall fees they paid and whether they thought the fees they paid were value for money in comparison to the health outcome. 
Multiple factors can affect patient's perception on the fees they paid. With negative perception on the above it can be concluded that there is sufficient evidence to challenge private sector healthcare satisfaction level vs price/fees equilibrium in Sri Lanka. Private sector healthcare regulators should play an important role in investigating whether there are any instances of over pricing and establishing a better framework to encourage patients to complain if they are dissatisfied with the fees they pay

\section{References}

1. Amarasinghe S, De Alwis S, Saleem S, Rannan-Eliya RP, Dalpatadu S. Private Health Sector Review 2012. IHP Technical Report Series, Number 2. Institute of Health Policy (revised edition), Colombo, Sri Lanka

2. Government of Sri Lanka. Annual Health Bulletin. Ministry of Health and Indigenous Health Services, Sri Lanka, 2017.

3. Rannan-Eliya RP, Wijemanne N, Liyanage I, Jayanathan J, Dalpatadu S, Amarasinghe S, Anuranga S. The quality of outpatient primary care in public and private sectors in Sri Lanka - how well do patient perceptions match reality and what are the implications? Health Policy and Planning, Volume 30, Issue suppl_1, March 2015, Pages i59 i74i74, doi.org/10.1093/heapol/czu115. Epub 2014 Oct 29.

4. Rannan-Eliya RP, Wijemanne N, Liyanage IK, Dalpatadu S, de Alwis S, Amarasinghe S, Shanthikumar S. Quality of inpatient care in public and private hospitals in Sri Lanka. Health Policy and Planning, Vol suppl_1, March 2015, Pages i46-i58

5. Andaleeb SS, Siddiqui N, Khandakar S. Patient satisfaction with health services in Bangladesh. Health Policy and Planning 2007;22:263-273 . Oxford University Press in association with The London School of Hygiene and Tropical Medicine, 2007. 2

6. Andaleeb SS. Public and private hospitals in Bangladesh: service quality and predictors of hospitals choice. Health Policy and Planning 15: 95-102, 2000a

7. Andaleeb SS. Service quality in public and private hospitals in urban Bangladesh; a comparative study. Health Policy 53: 25-37, 2000b.

8. Andaleeb SS. Service quality perceptions and patient satisfaction: a study on hospitals in a developing country. Social Science and Medicine 52: 1359-70, 2001.

9. Bilawka E. Craig BJ. Quality assurance in healthcare: past, present and future. International Journal. Dent Hygiene 1,2003,159-168, 2003. 3

10. Beauvais B, Gilson G, Schwab S, Jaccaud B, Pearce T, Holmes T. Overpriced? Are hospital prices associated with the quality of care? Healthcare 2020. 8, 135, 2020. 4

11. Rahman MM, Shahidullah $M$, Shahiduzzaman $M$, Rashid HA. Quality of healthcare from patient perspectives. Bangladesh Medical Research Council Bulletin 28: 87-96 5

12. Donabedian A. The quality of care: how can it be assessed? Journal of the American Medical Association 260: 1743-8, 1988. 6

13. Bucatariu L. George BP. Patient perception and choice factors related to international hospitals: A study on Ho Chi Minh City, Vietnam. J Health Med Informat $8: 277,2017.7$

14. Aldana MJ, Piechilek H, Sabir AA. Client satisfaction and quality of healthcare in rural Bangladesh. Bulletin of World Health Organization 79: 512-6, 2001 . 8

15. Schlossberg H. Health care looks for 'hero' in marketing, Marketing news, vol,24 pg.8. Google Scholar, 1990. 9

16. Wong WK. Cost to remain driving force of health care in the 1990s. Marketing news, vol.24. pg.8.Google Scholar, 1990. 10 